\title{
Germanica
}

\section{Ewald Palmetshofer, Faust hat hunger und verschluckt sich an einer grete}

Toulouse (Université de Toulouse-Le Mirail), Presses Universitaires du Mirail, 2011, 204 p., ISBN : 978-2-8107-0146-9, $17 €$.

Faust a faim immangeable marguerite

\section{Marc Lacheny}

\section{CpenEdition} Journals

Édition électronique

URL : http://journals.openedition.org/germanica/1437

DOI : $10.4000 /$ germanica. 1437

ISSN : 2107-0784

Éditeur

Université de Lille

Édition imprimée

Date de publication : 31 décembre 2011

ISBN : 9782913857285

ISSN : 0984-2632

Référence électronique

Marc Lacheny, "Ewald Palmetshofer, Faust hat hunger und verschluckt sich an einer grete », Germanica [En ligne], 49 | 2011, mis en ligne le 25 janvier 2013, consulté le 06 octobre 2020. URL http://journals.openedition.org/germanica/1437 ; DOI : https://doi.org/10.4000/germanica.1437

Ce document a été généré automatiquement le 6 octobre 2020.

(c) Tous droits réservés 


\section{Ewald Palmetshofer, Faust hat hunger und verschluckt sich an einer grete}

Toulouse (Université de Toulouse-Le Mirail), Presses Universitaires du Mirail, 2011, 204 p., ISBN : 978-2-8107-0146-9, $17 €$.

Faust a faim immangeable marguerite

Marc Lacheny

\section{RÉFÉRENCE}

Ewald Palmetshofer, Faust hat hunger und verschluckt sich an einer grete

\section{NOTE DE L'ÉDITEUR}

introduction de Sylvie Arlaud

1 Après avoir fait découvrir au public français des textes inédits de Kerstin Specht, Dirk Dobbrow, Sibylle Berg, Ulrike Syha, Falk Richter, Rebekka Kricheldorf, Kathrin Röggla, Moritz Rinke, Martin Heckmans, Anja Hilling et Philipp Löhle, la collection « Nouvelles Scènes Allemand», résolument tournée vers le théâtre contemporain de langue allemande, consacre cette fois un volume à une pièce mordante du jeune dramaturge autrichien Ewald Palmetshofer (né en 1978 en Basse-Autriche), Faust hat hunger und verschluckt sich an einer grete, soigneusement traduite par Laurent Muhleisen, Catherine Mazellier et Hilda Inderwildi.

2 Une pièce antérieure, Hamlet ist tot. Keine schwerkraft, valut à Palmetshofer d'être nommé meilleur espoir de l'année 2008 par la célèbre revue Theater heute. Créée en avril 2009, Faust hat hunger fournit à l'auteur l'occasion de poursuivre son dialogue avec les classiques - Goethe succédant ici à Shakespeare - et de soulever la question de la quête 
du bonheur humain dans un monde post-nietzschéen où Dieu est mort, autrement dit la question du tragique contemporain dans une société évoluant par-delà le bien et le mal. Le dialogue avec le Faust de Goethe est amorcé, comme le signale Sylvie Arlaud dans sa très belle et substantielle préface ("faust hat hunger: un reader's digest? ", p. 9-36, ici: p.9), dès le titre de la pièce: le terme de grete renvoie à la fois au personnage goethéen de Gretchen et à l'arête du poisson avec laquelle Faust s'étouffera peut-être. Par ce jeu de mots initial, Palmetshofer introduit déjà une forme de désacralisation visant à faire basculer les personnages humains, trop humains, de Goethe de leur piédestal classique pour les intégrer dans la banalité du quotidien. En outre, le prélude au théâtre du premier Faust se voit ici remplacé par un prélude à la télévision, la scène suivante constituant un pastiche du prologue dans le ciel: l'indication topographique "pas de ciel» renvoie tant à la traversée du néant entreprise par les six personnages qu'à l'image de la chute (p. 52 sq.), symboles d'un monde moderne privé de certitudes et de repères transcendantaux : « nous sommes des latrines, tous égaux, que le monde s'engouffre dans notre vide intérieur et le traverse » (p. 77).

Par le jeu de mots « cannibalique » du titre, Palmetshofer s'inscrit également dans une seconde filiation, toute autrichienne, inaugurée par Nestroy avec sa dernière pièce (Häuptling Abendwind oder Das gräuliche Festmahl, 1862) et poursuivie notamment par George Tabori (Die Kannibalen, Mein Kampf), Werner Schwab (Übergewicht, unwichtig: Unform) ou encore Elfriede Jelinek (Präsident Abendwind, Krankheit oder moderne Frauen, Raststätte, Stecken, Stab und Stangl), chez qui « l'ingurgitation de l'autre est la métaphore de son annihilation par le désir de possession» (p.11). Palmetshofer substitue aux personnages humains de Goethe des individus réifiés, jusque dans les rapports amoureux, produits d'une société capitaliste et utilitariste qui réduit l'autre au simple rang d'objet ou de marchandise. Corrigeant Hobbes, il constate froidement : «L'homme n'est pas un loup pour l'homme. Il est un produit pour lui, la marchandise totale.» De fait, les personnages de Heinrich et de Grete, pivot autour duquel sont bâties les 25 scènes qui composent la pièce, s'éprennent certes l'un de l'autre, mais, une fois que l'acte a été consommé, Heinrich délaisse la jeune femme comme s'il s'agissait d'un simple objet que l'on jette après utilisation. Dans une grande variété de styles et de tons (les conversations décousues, la langue elliptique et la structure fragmentaire cohabitent avec des envolées grandiloquentes débouchant sur le néant), héritée là encore de la tradition littéraire autrichienne allant de Nestroy à Jelinek en passant par Kraus, l'histoire des deux personnages inspirée du Faust de Goethe est narrée par trois couples d'amis - Paul et Inès, Fritz et Anne, Robert et Tania -, narration fragmentée qui brise sans cesse la linéarité dramatique de l'écriture. Ainsi, la pièce de Palmetshofer oscille constamment entre la platitude des dialogues entre voisins (voir notamment sc. 1, p. 64 sqq.) - reflet de la vacuité de mécanismes sociaux régis non par la volonté affichée d'intégration au sein du «corps collectif» (p. 91), mais par des rapports de pouvoir et de domination - et la complexité des monologues de Grete et de Heinrich joués par d'autres personnages (sc. 2, 6, 8, 11, 13, 16, 22).

4 En guise de postface, la pièce est suivie (p. 195-200) d'un entretien fort éclairant de Catherine Mazellier avec l'auteur dans lequel ce dernier revient notamment sur sa conception des relations humaines et la notion de bonheur, sur ses rapports avec l'hypotexte goethéen, ainsi que sur sa vision (politique et non psychologique) du théâtre et du langage. 
5 Le public français a pu découvrir la pièce de Palmetshofer au Théâtre Sorano de Toulouse les 10 et 11 mai derniers, jouée par la Compagnie de la Vieille Dame (mise en scène de Thomas Niklos), à l'occasion des Neuvièmes Rencontres du Théâtre Allemand Contemporain dans le cadre du festival Universcènes. Il reste à souhaiter tant à la traduction de la pièce de Palmetshofer qu'à la collection " Nouvelles Scènes Allemand » dirigée par Hilda Inderwildi et Catherine Mazellier de continuer à connaître un succès qu'elles méritent amplement. 